This item was submitted to Loughborough's Research Repository by the author.

Items in Figshare are protected by copyright, with all rights reserved, unless otherwise indicated.

\title{
Utilizing GRACE-based groundwater drought index for drought characterization and teleconnection factors analysis in the North China Plain
}

PLEASE CITE THE PUBLISHED VERSION

https://doi.org/10.1016/j.jhydrol.2020.124849

\section{PUBLISHER}

Elsevier BV

VERSION

AM (Accepted Manuscript)

\section{PUBLISHER STATEMENT}

This paper was accepted for publication in the journal Journal of Hydrology and the definitive published version is available at https://doi.org/10.1016/j.jhydrol.2020.124849.

\section{LICENCE}

CC BY-NC-ND 4.0

\section{REPOSITORY RECORD}

Wang, Fei, Zongmin Wang, Haibo Yang, Danyang Di, Yong Zhao, and Qiuhua Liang. 2020. "Utilizing Gracebased Groundwater Drought Index for Drought Characterization and Teleconnection Factors Analysis in the North China Plain". Loughborough University. https://hdl.handle.net/2134/12630170.v1. 


\section{Utilizing GRACE-based groundwater drought index for}

\section{2 drought characterization and teleconnection factors}

3 analysis in the North China Plain

4 Fei Wang a, Zongmin Wang a , Haibo Yang ${ }^{\text {a,*}, \text { Danyang Di a , Yong Zhao }}{ }^{\text {b,*, }}$, Qiuhua

$5 \quad$ Liang ${ }^{\mathbf{c}}$

a School of Water Conservancy Engineering, Zhengzhou University, Zhengzhou 450001, China

b State Key Laboratory of Simulation and Regulation of Water Cycle in River Basin, China Institute of Water Resources and Hydropower Research, Beijing 100038, China

c School of Architecture, Building and Civil Engineering, Loughborough University, Loughborough LE11 3TU, UK

*Correspondence: yanghb@zzu.edu.cn (H. Yang), zhaoyong@iwhr.com (Y. Zhao).

Abstract: Traditional drought monitoring methods rely on ground station data, which are difficult to reflect large-scale dynamic drought information. Thus, Gravity Recovery and Climate Experiment (GRACE) gravity satellite technology is applied to monitor and estimate drought, which can provide new data sources and measurement instruments for drought investigation. In this study, the GRACE groundwater drought index (GGDI) was utilized as a metric for assessing drought. The temporal evolution, spatial distribution and trend characteristics of drought were comprehensively identified in the North China Plain (NCP) from 2003 to 2015. Subsequently, the links between GGDI and teleconnection factors were clarified using cross wavelet transform technology. The results indicated that: (1) the quantitative results of GRACE were reliable and robust for drought evaluation; (2) the most serious drought event occurred from August 2013 to September 2014, with an average GGDI value of -1.36 ; (3) the monthly and seasonal droughts were increasing based 
on the modified Mann-Kendall (MMK) trend test method; and (4) the cross wavelet transform revealed that teleconnection factors had significant influences on drought evolution, and El Niño-Southern Oscillation (ENSO) had the strongest impact on drought in the NCP. This study sheds new insights into drought monitoring by using GRACE gravity satellite, which can be applied in other regions as well.

Keywords: GRACE gravity satellite; Drought; GGDI; Cross wavelet transform; North China Plain

\section{Introduction}

Drought is one of the most common natural disasters in the world, which has the characteristics of high frequency, long duration and extensive influences (Vicente-Serrano et al., 2010; Mishra and Singh, 2011; AghaKouchak et al., 2015; Zhang and He, 2016). The frequent occurrence and long-term persistence of drought will not only bring enormous losses to industrial and agricultural production, but also cause many adverse effects such as water resources shortage, land desertification and ecological environment deterioration (Xu et al., 2010; Zhang et al., 2017). Therefore, it is crucial and urgent to monitor and evaluate drought effectively. Traditional drought monitoring methods are mostly based on the station-observed meteorological and hydrological data, and the spatial distribution of drought is obtained by interpolation. However, due to the spatial heterogeneity of regional environment and the scarcity of station observation data, the accuracy of drought distribution characteristics obtained by spatial interpolation is not very high, which is difficult to reflect the large-scale dynamic drought information (Long et al., 2014). In addition, some drought indices are only calculated by using a single variable (e.g., precipitation, soil moisture, or surface runoff), which may not reflect the actual situation of drought disaster accurately and comprehensively (Thomas et al., 2014; Ma et al., 2017). 
With the rapid development of earth observation based on remote sensing technology, the original drought monitoring method based on ground station can be improved to realize large-scale drought assessment at the regional scale (Wang et al., 2018a). Gravity Recovery and Climate Experiment (GRACE) remote sensing satellites are cooperatively developed by National Aeronautics and Space Administration (NASA) and the German Aerospace Center, which use twin satellites to speculate global water storage changes (WSC) by making detailed measurements of earth gravity field (Long et al., 2014; Sinha et al., 2019). GRACE satellites provide a new way for the retrieval of terrestrial water storage changes (TWSC), and also extend a new approach for the study of hydrological drought. Compared with the conventional univariate indicator, GRACE-obtained terrestrial water storage contains surface water storage, groundwater storage, soil moisture storage, snow water equivalent and canopy water storage (Zhang et al., 2019). Thus, the development of GRACE gravity satellite technology has realized the dynamic observation of large-scale regional water resources changes, which can reflect all water resources information (i.e., groundwater, surface water, soil moisture, etc.) and provide an additional data source for drought study (Rowlands et al., 2005). Also, as an effective instrument for monitoring drought, GRACE breaks through the limitation of traditional ground observation on the temporal and spatial scale, and has been widely used in regional drought investigation. Based on terrestrial moisture changes retrieved from GRACE, Yirdaw et al. (2008) proposed a new total storage deficit index for drought characterization in the Canadian Prairie. Yi and Wen (2016) established a GRACE-based Hydrological Drought Index (GHDI) for drought monitoring in the continental United States from 2003 to 2012, and discovered that GHDI could be extended for global drought monitoring due to its feasibility. Sun et al. (2018) evaluated drought using the GRACE terrestrial water storage deficit over the Yangtze River Basin, China, and indicated that GRACE data could provide considerable insights for drought evaluation. Hosseini-Moghari et al. (2019) introduced 
modified total storage deficit index (MTSDI) for drought monitoring using GRACE observations in the Markazi Basin, and found that MTSDI identified two drought events that coincided with the actual droughts.

Although there are many researches on the identification of drought characteristics using GRACE data, these studies only verify that GRACE has the ability of drought monitoring, and do not explore the relationships between GRACE-identified drought and teleconnection factors. Teleconnection factors are strong signals caused by the interaction between ocean and atmospheric circulation in the process of global change, which influence the exchange process of the mass, momentum and heat in the atmosphere, and then give rise to the climate anomalies (Ma et al., 2018). Previous studies have demonstrated that teleconnection factors have a profound impact on drought, which will change the complex drought structure (Trenberth and David, 2001; Dai, 2011; Wang et al., 2015). Huang et al. (2016) discovered that Arctic Oscillation (AO) and El Niño-Southern Oscillation (ENSO) had significant influence on hydrological drought in the Columbia River Basin. Asong et al. (2018) concluded that drought was closely related to AO, ENSO and Pacific Decadal Oscillation (PDO) in cold regions. In addition, sunspots affect the drought distribution through influencing regional radiation and changing the state of water and heat balance (Fu et al., 2012). Thus, teleconnection factors may directly and indirectly impact the occurrence of drought, which deserve to be further investigated.

As the most seriously restricted area by water resources in the process of China's economic development, the North China Plain (NCP) is also one of the areas that are extremely dependent on groundwater resources (Gong et al., 2018). The vast NCP has become the largest underground funnel area in the world due to groundwater over-exploitation for many years, where irrigation has severely depleted groundwater resources at a rate of approximately $4 \mathrm{~km}^{3} / \mathrm{yr}$ since the 1960s (Cao et al., 2016). Numerous studies demonstrated that drought was increasing under the influence of climate change and 
human activities in the NCP, and was expected to rise in frequency, duration and severity (Li et al., 2017; Liu et al., 2018; Wang et al., 2018b). Nevertheless, the systematic investigation of GRACE-based drought characteristics has not been carried out in the NCP. Furthermore, as far as we know, no investigations on identifying the relationships between drought and teleconnection factors have been conducted in this region. To fill this research gap, this present study aims to explore the drought situation in the NCP during 2003-2015 by using GRACE groundwater drought index (GGDI), and reveal the relationships between drought and teleconnection factors.

The primary purposes of this study are (1) to verify the accuracy of GRACE results; (2) to utilize GRACE-based GGDI for exploring the temporal evolution and spatial distribution of drought; (3) to identify the drought trend characteristics at the grid scale in the NCP during 2003-2015; and (4) to clarify the links between GGDI and teleconnection factors using cross wavelet transform method. The research results can accurately capture drought characteristics using GRACE-based GGDI, which can be applied in other regions as well.

\section{Study area and data}

\subsection{Study area}

The NCP is the second largest plain in China, crossing five administrative regions including Beijing (BJ), Tianjin (TJ), Hebei (HB), Shandong (SD) and Henan (HN), with altitude increasing gradually from southeast to northwest (Fig. 1a). The NCP lies between $110^{\circ} 21^{\prime}-122^{\circ} 42^{\prime} \mathrm{E}$ and $31^{\circ} 23^{\prime}-43^{\circ} 37^{\prime} \mathrm{N}$, covering a total area of approximately $540,000 \mathrm{~km}^{2}$. As a momentous political, economic and cultural center of China, the NCP has prominent water resource contradictions and drought problems. Meanwhile, it is a major grain production region in China, and $80 \%$ of the land areas are cropland (Fig. 1b). The average annual precipitation ranges between 400 and $600 \mathrm{~mm}$ and most of the precipitation occurs in the summer season from June to August (Hu, 2013). Additionally, the rapid development of industrial and agricultural production and the continuous population growth make the 
water resources shortage become one of the important factors affecting the economic development of this region. Within recent years, large-scale overexploitation of groundwater in the NCP has seriously changed the regional water circulation conditions, led to the deterioration of human living environment, and caused a series of ecological environment problems, such as land subsidence, seawater intrusion and river exhaustion. Over-exploitation of groundwater results in dramatic changes in the quantity, quality and spatio-temporal distribution of water resources, accompanied by a series of drought phenomena (Feng et al., 2013). Thus, it is of great significance and practical value to study groundwater drought in the NCP.


Fig. 1. The location and elevation (a) and landuse types (b) over the North China Plain (NCP).

\subsection{Data}

2.2.1. Gravity recovery and climate experiment (GRACE) 
At present, GRACE gravity satellite data are mainly derived from the Center for Space Research at the University of Texas (CSR), the German Research Center for Geosciences (GFZ) and the Jet Propulsion Laboratory (JPL). There are two primary methods to calculate the terrestrial water storage anomalies (TWSA) by using GRACE data: the spherical harmonic coefficients (SHC) method based on GRACE Level-2 gravity field, and the mass concentration (mascon) solutions based on GRACE Level 1B data (Wu et al., 2019). Although the SHC method is easy to be realized, the mass variation obtained by this method has obvious strip and high-frequency error, due to the observation error of GRACE satellite and the error in the process of solving the earth gravity field model (Swenson and Wahr, 2006). The new mascon solutions directly calculate the equivalent water height (EWH) corresponding to the mass change of a certain region through the high-precision GRACE satellite observation data. Additionally, mascon solutions have removed glacial isostatic adjustment, with no need for north-south striping and filtering (Scanlon et al., 2016). In this work, the most recent version of GRACE RL06 CSR mascon solutions during 2003-2015 was used to evaluate the TWSA, with a spatial resolution of $0.25^{\circ} \times$ $0.25^{\circ}$ (derived from http://www2.csr.utexas.edu/grace). The TWSA reported in these mascon solutions are relative to a mean time baseline from 2004 through 2009, with negative values meaning dryer than normal, and positive values meaning wetter than normal. For the missing data in some months due to technical issues, linear interpolation method was adopted to fill the data based on the neighboring months (Lin et al., 2019; Wu et al., 2019). Linear interpolation is a relatively simple interpolation method, which can get the linear equation from the known value and obtain the missing value by solving the linear equation. This method is effective, prevalent and widely used to handle missing data.

\subsubsection{Global land data assimilation system (GLDAS)}

Global land data assimilation system (GLDAS) is a cooperative program developed by NASA and National Oceanic and Atmospheric Administration (NOAA) (Rodell et al., 
2004). GLDAS adopts advanced data assimilation technology to integrate satellite and ground observation data into a unified model, including four land surface models, namely Noah, Mosaic, Community Land Model (CLM) and Variable Infiltration Capacity (VIC) model. These models contain a variety of land surface field information in the form of gridded data, such as global precipitation, temperature, evapotranspiration, surface runoff, soil moisture, etc. In addition, GLDAS data has high accuracy and is suitable for GRACE verification (Cao et al., 2015; Yang and Chen, 2015). Only GLDAS Noah model has the highest spatial resolution $\left(0.25^{\circ} \times 0.25^{\circ}\right)$ consistent with GRACE RL06 CSR mascon solutions, thus, this paper adopts GLDAS Noah model L4 monthly V2.1 products (derived from http://disc.sci.gsfc.nasa.gov/hydrology/data-holdings) during 2003-2015 for GRACE verification.

\subsubsection{Tropical rainfall measuring mission (TRMM)}

Tropical rainfall measuring mission (TRMM) dataset is the most widely used precipitation product, which has become one of the important sources of gridded precipitation data and has been widely used in meteorological, hydrological, ecological and other research fields (Huffman et al., 2007). The appearance of TRMM satellite precipitation products can make up for the deficiency of precipitation data in areas with sparse ground station and non-radar coverage, and help us better understand the spatio-temporal distribution characteristics of precipitation. Moreover, TRMM 3B43 product is a gauge-corrected and post-real time research product with a spatial resolution of $0.25^{\circ} \times 0.25^{\circ}$ (Sun et al., 2018). In this study, we selected the monthly TRMM 3B43v7 gridded precipitation data (derived from https://pmm.nasa.gov/data-access/downloads/trmm) from 2003 to 2015, in order to reflect the precipitation information and the relationship between drought and precipitation in the NCP.

2.2.4. Climate data 

and sunspot data. For ENSO, we selected Multivariate ENSO Index (MEI) obtained from the NOAA Earth System Research Laboratory (https://www.esrl.noaa.gov/psd/enso/mei). The monthly PDO and AO data were derived from the NOAA National Centers for

Table 1

Data sources of ENSO, PDO, AO and sunspot.

\begin{tabular}{|c|c|c|}
\hline Climate data & Time period & Source \\
\hline ENSO & $2003-2015$ & https://www.esrl.noaa.gov/psd/enso/mei \\
\hline PDO & 2003-2015 & http://www.ncdc.noaa.gov/teleconnections/pdo/ \\
\hline $\mathrm{AO}$ & $2003-2015$ & http://www.ncdc.noaa.gov/teleconnections/ao/ \\
\hline Sunspot & $2003-2015$ & http://www.sidc.be/sunspot-data \\
\hline
\end{tabular}

\section{Methodology}

\subsection{Retrieval of groundwater storage change}

The GRACE-based TWSA is the total change of groundwater, soil moisture, snow water, canopy water and surface water. In order to investigate the groundwater changes using GRACE gravity satellite, the groundwater storage anomalies (GWSA) in the study area can be obtained by deducting the contribution of the soil moisture storage anomalies (SMSA), snow water equivalent anomalies (SWEA), canopy water storage anomalies (CWSA) and surface water storage anomalies (SWSA) provided by GLDAS model from the GRACE-based TWSA (Zhang et al., 2019). The GRACE and GLDAS are monthly data, with a unit of millimeter. The calculation method of GWSA is as follows: 

the dimensionless GGDI was adopted to investigate the characteristics of groundwater drought. Firstly, a monthly climatology $C_{i}$ is calculated as follows:

$$
C_{i}=\frac{1}{n_{i}} \sum_{1}^{n_{i}} G W S A_{i}
$$

\begin{tabular}{ccc}
\hline Grade & Classification & GGDI \\
\hline I & No drought & $-0.5<$ GGDI \\
II & Mild drought & $-1.0<$ GGDI $\leq-0.5$ \\
III & Moderate drought & $-1.5<$ GGDI $\leq-1.0$ \\
IV & Severe drought & $-2.0<$ GGDI $\leq-1.5$ \\
V & Extreme drought & GGDI $\leq-2.0$ \\
\hline
\end{tabular}

where $C_{i}$ is the climatology for month $i(i=1,2, \ldots, 12)$.

Then, we use monthly climatology to remove the influence of seasonality in groundwater storage changes (Thomas et al., 2017). The monthly climatology is subtracted from GWSA to obtain a groundwater storage deviation (GSD), which represents the net deviation in the volume of groundwater storage based on seasonal variability. Finally, the GSD is normalized by removing the mean $\bar{x}_{G S D}$ and dividing by the standard deviation $s_{G S D}:$

where GGDI is the normalized net deviation in groundwater storage volumes, and can be used as a metric of groundwater drought to reflect the drought situation. The classification of the GGDI is shown in Table 2.

Table 2

Classification of the GGDI used in this study.

\subsection{Singular spectral analysis (SSA)}



reconstruction of time series and associated with empirical orthogonal function (Ghil et al., 2002; Walwer et al., 2016). The spatial structure decomposed by SSA method is closely related to the time scale, and the time series information can be extracted effectively from the finite time series with noise. Furthermore, SSA can extract oscillatory or meaningful components for sequence reconstruction, and identify the change process and trend item of time series. Compared with other methods, SSA does not have the problem of over-fitting, which is very suitable for analyzing the change characteristics of nonlinear time series. In this study, SSA was used to reflect the changes of GGDI time series. The detailed procedures are as follows: window $\mathrm{M}$, and the track matrix $\mathrm{X}$ is established:

$$
X=\left[\begin{array}{cccc}
x_{1} & x_{2} & \cdots & x_{N-M+1} \\
x_{2} & x_{3} & \cdots & x_{N-M+2} \\
\vdots & \vdots & \cdots & \vdots \\
x_{M} & x_{M+1} & \cdots & x_{N}
\end{array}\right]
$$

A time series with a sample size of $\mathrm{N}$ is arranged according to the length of moving where $\mathrm{X}$ is the track matrix, and $\mathrm{M}$ is the length of moving window.

Then, a matrix $\mathrm{XX}^{\mathrm{T}}$ is constructed for singular value decomposition, and the track matrix $\mathrm{X}$ is decomposed:

$$
x_{i+j}=\sum_{k=1}^{M} a_{i}^{k} E_{j}^{k}
$$

where $a_{i}^{k}$ is the time principal component, and $E_{j}^{k}$ is the relevant feature vector.

A set of feature vector with a length of $\mathrm{m}(\mathrm{m}<\mathrm{M})$ is selected, and the sequence is reconstructed:

$$
x_{i}^{k}=\left\{\begin{array}{cc}
\frac{1}{M} \sum_{j=1}^{M} a_{i j}^{k} E_{j}^{k} & M \leq i \leq N-M+1 \\
\frac{1}{i} \sum_{j=1}^{M} a_{i j}^{k} E_{j}^{k} & 1 \leq i \leq M-1 \\
\frac{1}{N-t+1} \sum_{j=i-N+M}^{M} a_{i j}^{k} E_{j}^{k} & N-M+2 \leq i \leq N
\end{array}\right.
$$




\subsection{The modified Mann-Kendall (MMK) trend test method}

The traditional Mann-Kendall (MK) trend test method, which is a nonparametric method recommended by the World Meteorological Organization, is widely used to analyze the trend of time series. However, the persistence of hydrometeorological series will disturb the results of MK test. The modified Mann-Kendall (MMK) trend test method can eliminate the autocorrelation of time series, and is more reliable and robust in obtaining the trend of hydrometeorological series (Guo et al., 2019; Wang et al., 2019). Therefore, this study adopted MMK method to identify the gridded drought trend characteristics in the NCP from 2003 to 2015. The detailed computational processes are as follows:

Dividing the sequence $X_{T}$ by the mean of the sequence, a new sequence $X_{t}$ with an average value of 1 is created. The trend estimator $\beta$ of the rank of the new sequence is calculated:

$$
\beta=\operatorname{median}\left(\frac{x_{i}-x_{j}}{i-j}\right) \quad 1 \leq i<j \leq n
$$

where $\beta<0$ shows a downward trend in the sequence, and $\beta>0$ shows an upward trend in the sequence.

Assuming that the trend item of the new sequence $X_{t}$ is linear $T_{t}$, the trend item is removed and the corresponding stationary sequence $Y_{t}$ is obtained:

$$
Y_{t}=X_{t}-T_{t}=X_{t}-\beta \times t
$$

The rank sequence corresponding to sequence $Y_{t}$ is calculated and its autocorrelation coefficient $r_{i}$ is calculated:

$$
r_{i}=\frac{\sum_{k=1}^{n-i}\left(R_{k}-\bar{R}\right)\left(R_{k+i}-\bar{R}\right)}{\sum_{k=1}^{n}\left(R_{k}-\bar{R}\right)^{2}}
$$

where $R_{i}$ is the rank of $y_{i}$, and $\bar{R}$ is the average rank.

Based on $r_{i}$, the variance $\operatorname{var}^{*}(S)$ of trend statistic $S$ of autocorrelation sequence is calculated: 


$$
\eta=1+\frac{2}{n(n-1)(n-2)} \times \sum_{i=1}^{n-1}(n-i)(n-i-1)(n-i-2) r_{i}
$$

$$
\operatorname{var}^{*}(S)=\eta \times \frac{n(n-1)(2 n+5)}{18}
$$

The test statistic $Z^{*}$ is given as:

$$
Z^{*}=\left\{\begin{array}{cc}
\frac{S-1}{\sqrt{\operatorname{var}^{*}(S)}} & S>0 \\
0 & S=0 \\
\frac{S+1}{\sqrt{\operatorname{var}^{*}(S)}} & S<0
\end{array}\right.
$$

For a given significance level $\alpha$, if $\left|Z_{s}\right|$ is less than $Z_{0.05 / 2}$, the original hypothesis is accepted. Otherwise, the original hypothesis is rejected; that is, the sequence has a significant upward or downward trend.

\subsection{Cross wavelet transform method}

Cross wavelet transform method is an effective signal analysis technology, which combines wavelet transform with cross spectrum analysis. It can effectively analyze the correlation between two time series, and can reveal the relationship between two sequences in time-frequency domain from the perspective of multiple time scales (Huang et al., 2015). Also, cross wavelet transform can reflect the region with the same energy spectrum after wavelet transform, thus revealing the significance of the interaction between the two time series in different time-frequency domain. In this study, the relationships between GGDI and teleconnection factors were investigated in the NCP using cross wavelet transform method. The cross wavelet transform of the two time series $x_{n}$ and $y_{n}$ can be described as $W^{X Y}=W^{X} W^{Y *}$, where * reveals their complex conjugation. The cross wavelet power is expressed as $\left|W^{X Y}\right|$. The complex argument arg $\left(W^{x y}\right)$ can be regarded as the local relative phase between $x_{n}$ and $y_{n}$ in time and frequency domains. The theoretical distribution of the 
cross wavelet power of the two time series with their background power spectra $P_{k}^{X}$ and $P_{k}^{Y}$ is expressed as follows:

$$
D\left(\left|\frac{W_{n}^{X}(s) W_{n}^{Y *}(s)}{\sigma_{X} \sigma_{Y}}\right|<p\right)=\frac{Z_{v}(p)}{v} \sqrt{P_{k}^{X} P_{k}^{Y}}
$$

where $Z_{v}(p)$ is the confidence level associated with the probability $p$ of a probability distribution function which is defined by the square root of two $\chi^{2}$ distributions (Torrence and Compo, 1998).

In addition, the flowchart of the identification of drought characteristics is shown in Fig. 2.

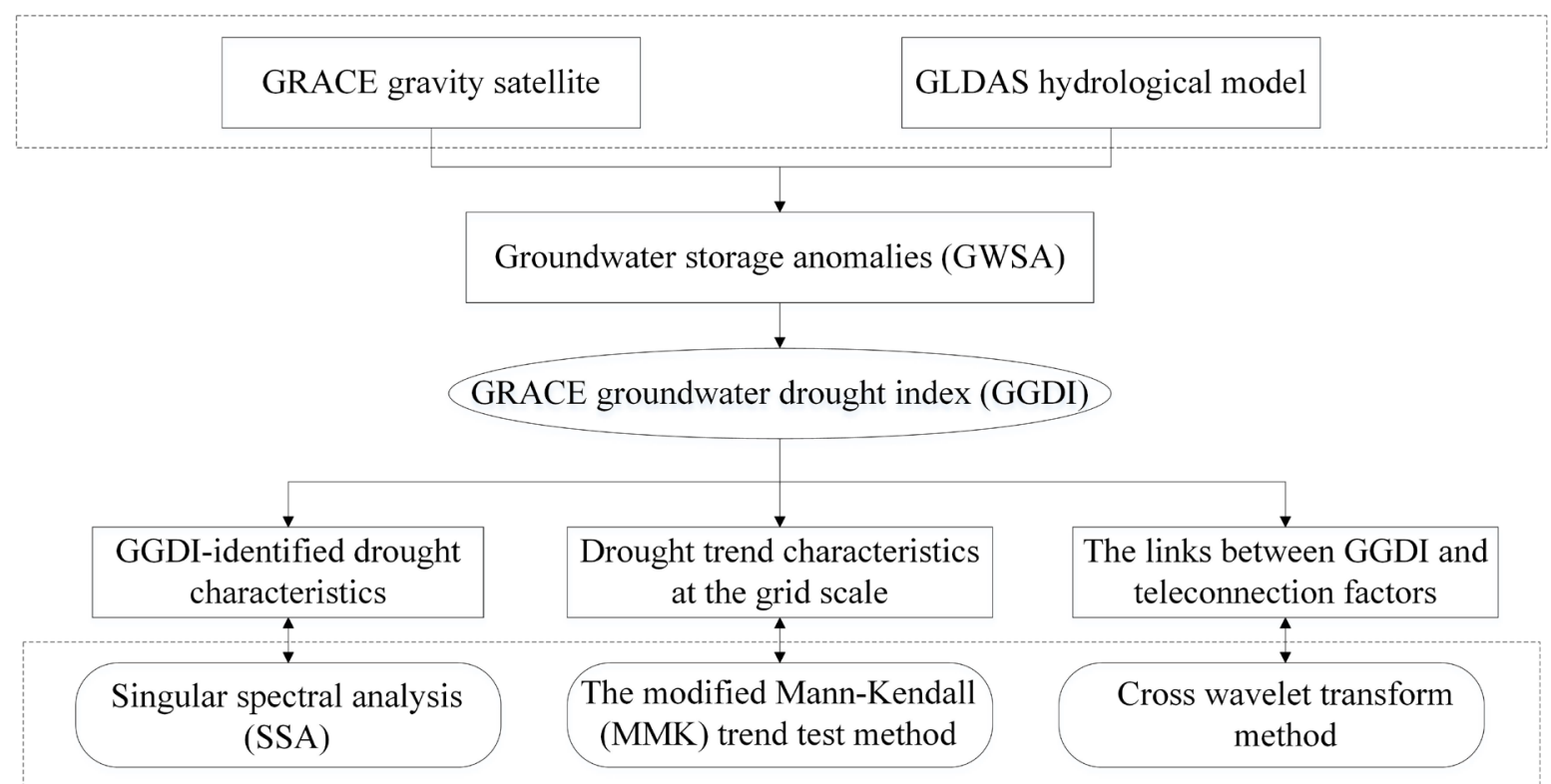

Fig. 2. Flowchart of the identification of drought characteristics.

\section{Results}

\subsection{GRACE verification}

It is necessary to verify the accuracy of results after obtaining TWSA based on GRACE, thus, GLDAS hydrological model is used for GRACE verification (Cao et al., 2015; Yang and Chen, 2015). The water storage changes (WSC) obtained from GRACE and GLDAS were basically consistent with a unit of EWH and had significant correlation $(P<0.05)$ in the NCP (Fig. 3). The amplitude of WSC obtained from GRACE ranged from 
-65.9 to $53.2 \mathrm{~mm}$, while that obtained from GLDAS ranged from -19.2 to $31.7 \mathrm{~mm}$ (Fig. 3a). This may be because the water storages obtained from GRACE are the sum of surface water and groundwater storages, with relatively larger variation amplitude, while those obtained from GLDAS do not contain groundwater. The GRACE uncertainty estimation was based on the approach suggested by Landerer and Swenson (2012), with an uncertainty value of $\pm 7.36 \mathrm{~mm} /$ month. In addition, the GRACE-based WSC exhibited a downward trend $(-0.12 \mathrm{~mm} / \mathrm{month})$, which was caused by the over-exploitation of groundwater or the soil moisture consumption due to the implementation of ecological restoration project. The ecological restoration project enhanced the vegetation coverage in the NCP, thus aggravating the direct consumption of soil moisture and groundwater. Generally, the correlation between precipitation and WSC was also favorable during 2003-2015. However, in addition to precipitation, the factors affecting water storages included surface runoff, groundwater and evapotranspiration. Besides, the response of WSC to precipitation had time lags, resulting in inconsistent fluctuations of precipitation and WSC in some periods. Noticeably, the least annual precipitation $(595.47 \mathrm{~mm})$ occurred in 2014 , with an average GRACE-based WSC reaching a minimum value $(-17.04 \mathrm{~mm})$. Additionally, the WSC obtained from GRACE and GLDAS were also consistent in each subzone of the NCP (Figs. 3b-f). Underlying surface conditions have different influences on the water circulation process in each subzone, which may be the main reason for the spatial discrepancy of WSC. The GRACE gravity satellite data were in good agreement with GLDAS hydrological model and precipitation data, and they all exhibited regular and differentiated fluctuations. In summary, the quantitative results of GRACE were reliable, which provided scientific foundation for further drought investigation in the NCP. 

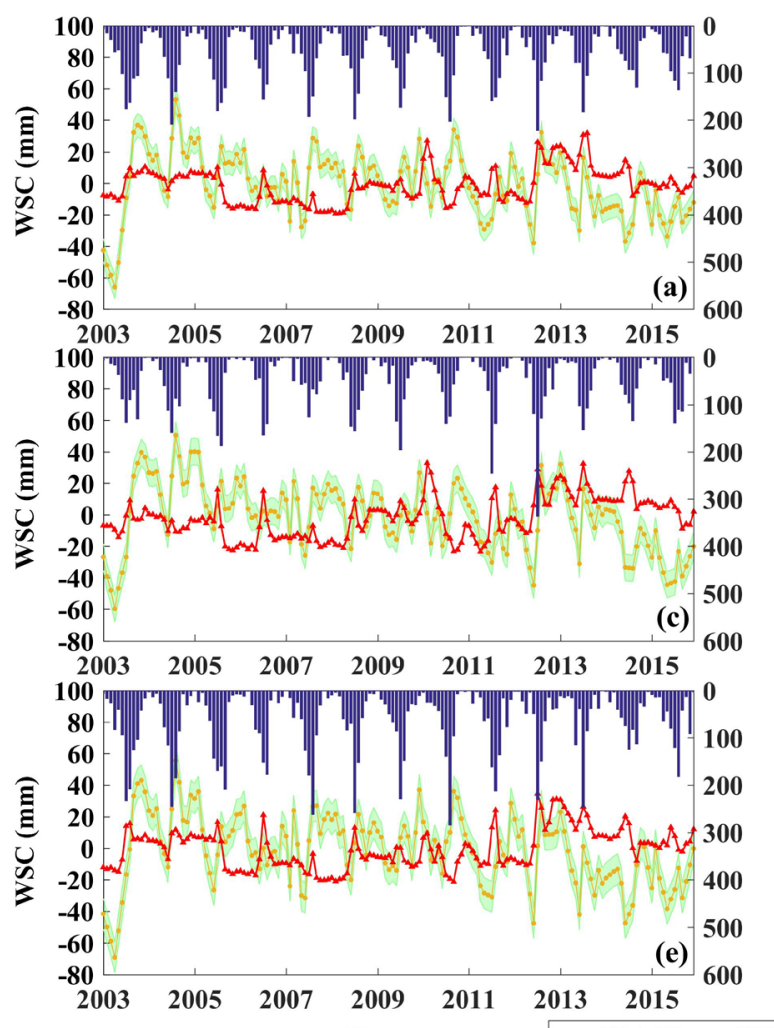

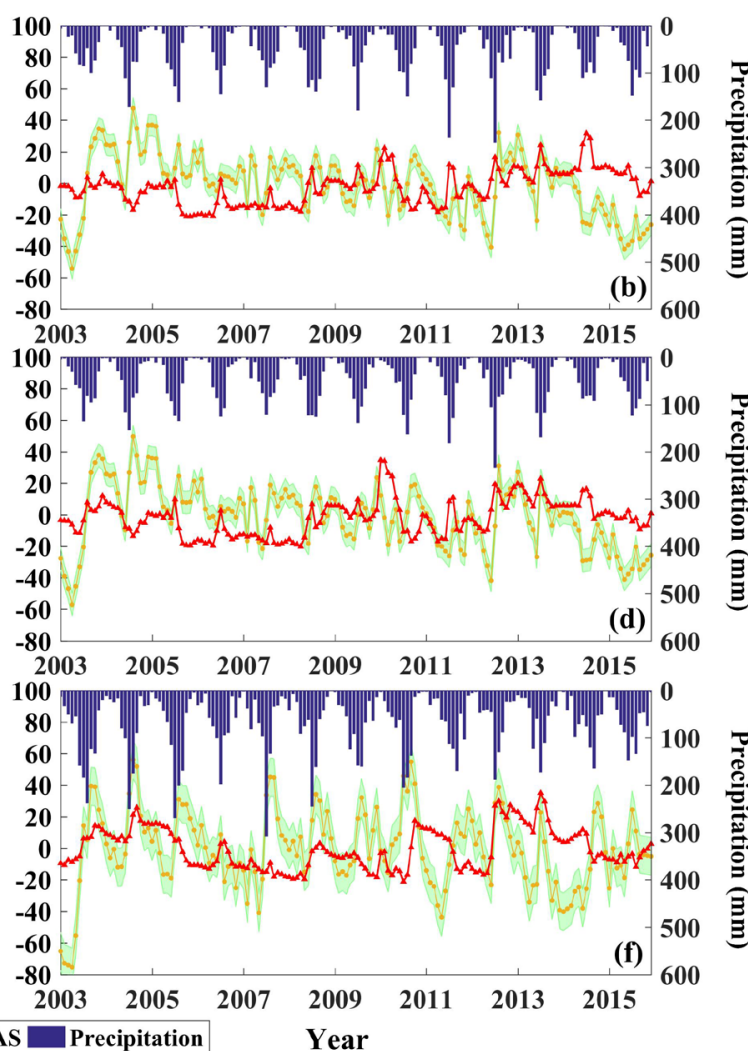

Fig. 3. Comparisons of GRACE and GLDAS during 2003-2015 in the NCP and its

subzones, viz. (a) NCP, (b) BJ, (c) TJ, (d) HB, (e) SD and (f) HN. Yellow lines:

GRACE; Red lines: GLDAS; Blue columns: monthly precipitation; Green shadows:

the uncertainties in GRACE.

\subsection{GGDI-identified drought characteristics}

\subsubsection{Temporal evolution of drought}

Fig. 4 illustrates the temporal evolution characteristics of drought in the NCP from 2003 to 2015 . The drought index GGDI showed a downward trend with different change characteristics in each subzone, indicating that the GGDI-identified drought was increasing in the NCP during 2003-2015. From the time series of GGDI, we can see that droughts have become more frequent in recent years, with the most serious drought event occurred during 2013.08-2014.09, which was consistent with the results of Zhao et al. (2019). Over the entire plain (Fig. 4a), the average GGDI reached -1.36 in this drought event (2013.08-2014.09), whilst the average GGDI reached 0.23 and -0.62 in the previous and 
later periods of this drought event. The worst drought occurred in July 2014, with a minimum GGDI value of -1.96 . As shown in Figs. 4b-f, the most significant upward trend of drought in each subzone occurred in TJ, with a GGDI linear tendency rate of $-0.14 / 10 \mathrm{a}$. During 2013.08-2014.09, the average GGDI values in BJ, TJ, HB, SD and HN were -1.47, $-1.50,-1.27,-1.41$ and -1.40 , respectively. On the monthly scale, the most severe drought in BJ, TJ and HB occurred in July 2014, with GGDI values of $-2.77,-2.40$ and -2.19 . And the most severe drought in SD and HN occurred in September 2013 and October 2013, with GGDI values of -2.01 and -2.24 , respectively. Furthmore, SSA was used to reflect the variation characteristics of GGDI time series. The changes of GGDI and SSA-derived trend item indicated a high consistency (Fig. 4) with Pearson correlation coefficient $(r)$ ranging from 0.87 to 0.91 under the significant level of $P<0.01$ for the period of 2003 to 2015 .

From the SSA-derived trend items, it can be seen that GGDI was decreasing, which also indicated that drought was increasing in the NCP during 2003-2015.
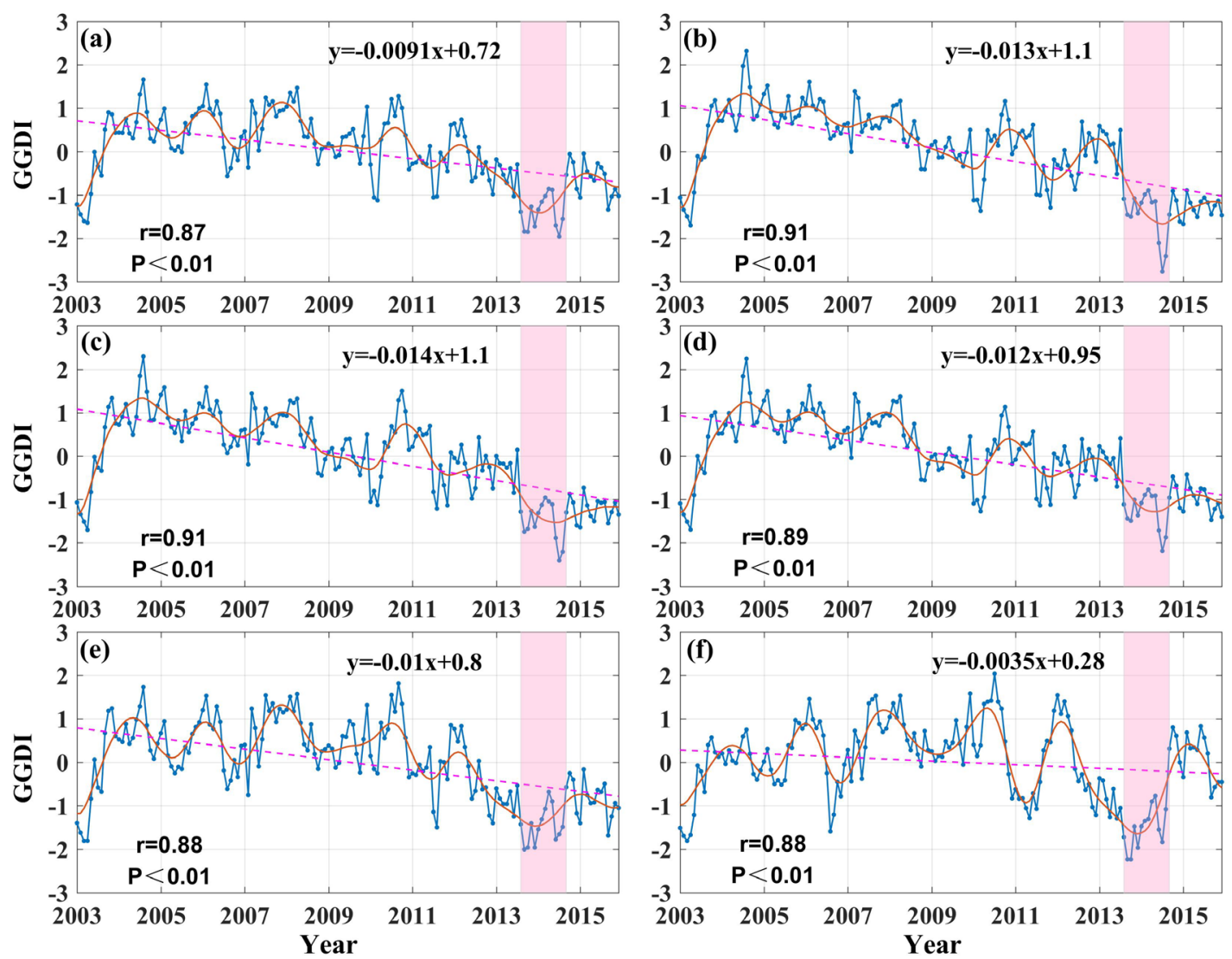
Fig. 4. Time series of GGDI during 2003-2015 in the NCP and its subzones, viz. (a) NCP, (b) BJ, (c) TJ, (d) HB, (e) SD and (f) HN. Blue lines: GGDI; Orange lines: SSA-derived trend items; Pink bands: the worst drought events. The dashed line is the trend of GGDI by linear regression, and $r$ shows that the correlation between GGDI and SSA-derived trend item is significant at the $99 \%$ level.

\subsubsection{Spatial distribution of drought}

As the worst drought event occurred during 2013.08-2014.09, in order to reflect the initiation and termination of this drought event, we also depicted the spatial distribution of drought in July 2013 and October 2014 in Fig. 5. On the monthly scale, the average GGDI values of all grids in the NCP during 2013.07-2014.10 were $-0.30,-1.39,-1.84,-1.85$, $-1.27,-1.72,-1.34,-1.16,-1.02,-0.86,-0.88,-1.70,-1.96,-1.55,-0.53$ and -0.05 , respectively. Obviously, the worst drought occurred in July 2014, with serious drought in almost the entire plain and an average GGDI value of -1.96 ; followed by October 2013 with an average GGDI value of -1.85 . Drought had been considerably relieved in October 2014 with a maximum GGDI value of -0.05 . Moreover, in each subzone, the worst drought with smallest GGDI values occurred in $\mathrm{HN}(-1.06), \mathrm{HN}(-1.72), \mathrm{HN}(-2.24), \mathrm{HN}(-2.24)$, HN (-1.48), HN (-1.97), SD (-1.54), HN (-1.35), HN (-1.31), BJ (-1.17), BJ (-1.14), BJ $(-2.10)$, BJ (-2.77), BJ (-2.41), BJ (-1.45) and BJ (-0.91), respectively (Figs. 5a-p). Consequently, relevant drought-resistant measures should be focused on in these subzones, in order to reduce the impact of drought disaster and improve the ability of drought resistance. 

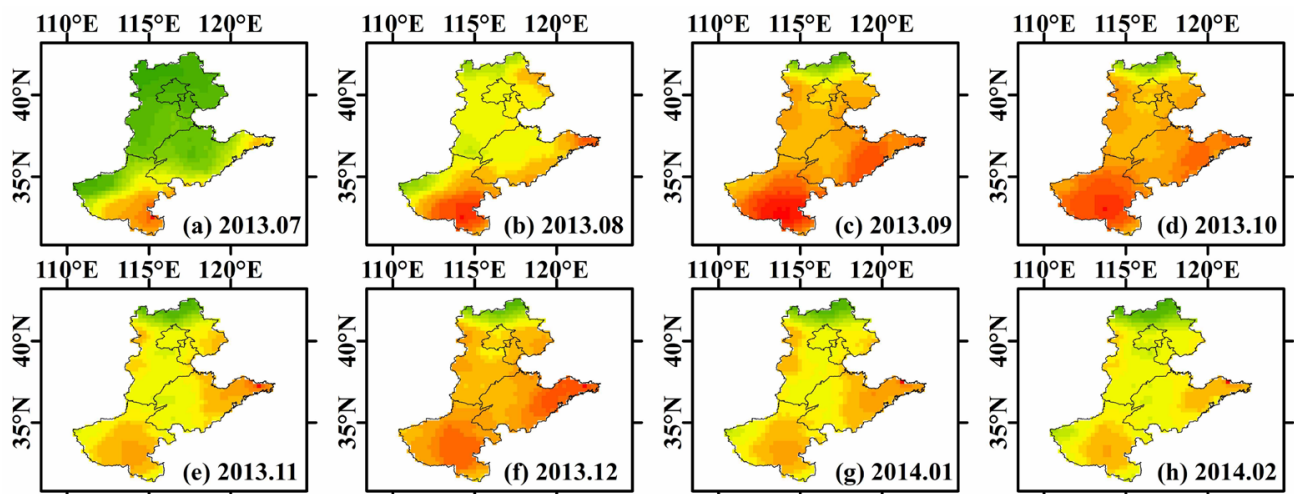

$N$
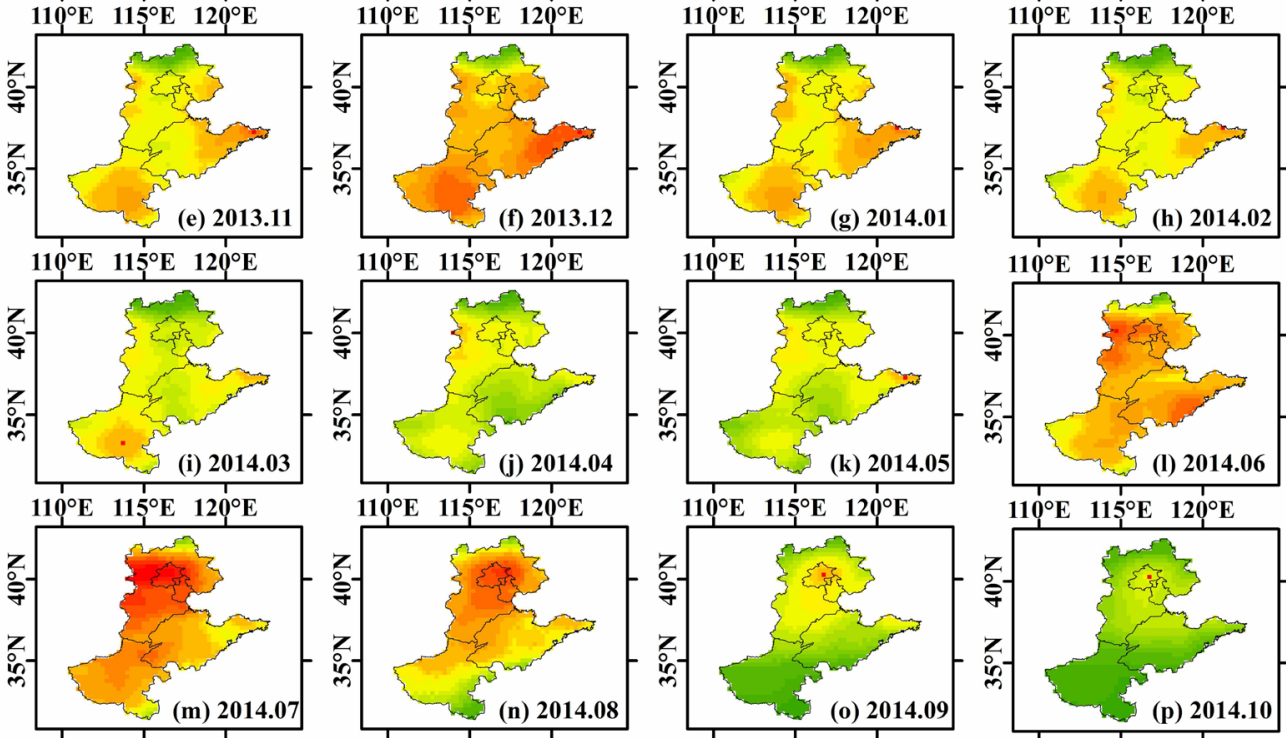

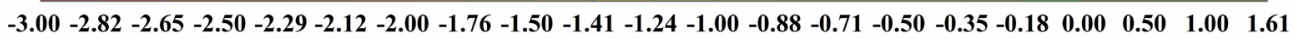
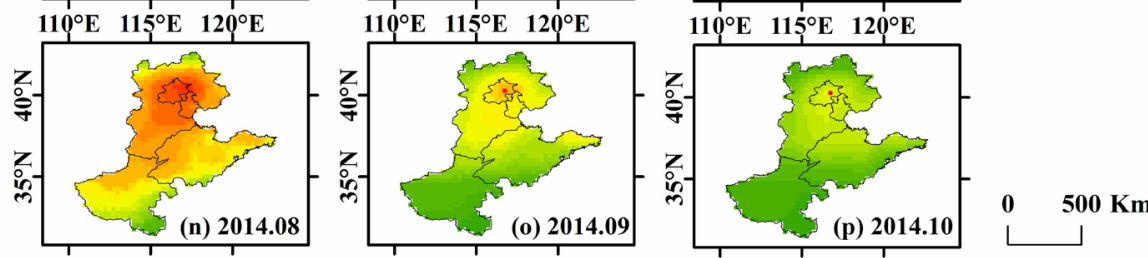

$500 \mathrm{Km}$

\section{GGDI}

Fig. 5. Spatial distribution of drought during 2013.07-2014.10 in the NCP, with

green and red colors indicating lighter and heavier drought, respectively.

\subsection{Drought trend characteristics at the grid scale}

The monthly and seasonal gridded drought trend characteristics based on the MMK trend test method are illustrated in Fig. 6. Fig. 7 shows the trend characteristic $Z_{s}$ values of

GGDI in the NCP during 2003-2015. On the monthly scale, the average $Z_{s}$ values of GGDI in the NCP from January to December were $-1.24,-0.59,-0.90,-0.66,-0.95,-1.21,-1.02$, $-1.17,-1.72,-1.59,-1.79$ and -1.76 , respectively. The GGDI showed a downward trend for all months, indicating that drought was generally increasing in the NCP during 2003-2015. From January to December, the drought area percentage with an upward trend ranged from $75.7 \%$ to $96.7 \%$. Among these 12 months, the significant drought increasing trend $(P<0.01)$ with the largest area percentage $(22.4 \%)$ occurred in December. On the seasonal scale, the average $Z_{s}$ values of GGDI in spring, summer, autumn and winter were $-0.89,-1.37,-1.76$ and -1.70 , suggesting that droughts were increasing for all seasons. 

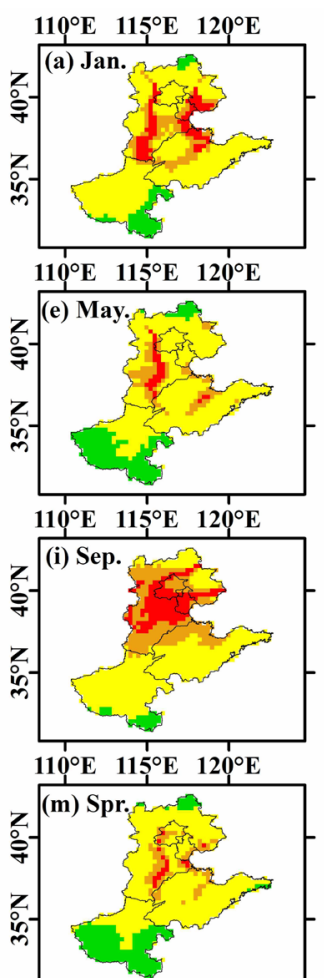

significant downward trend $(P<0.01)$

significant downward trend $(P<0.05)$

downward trend (no significant)

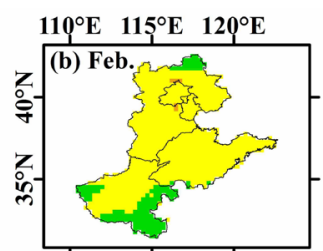

$110^{\circ} \mathrm{E} \quad 115^{\circ} \mathrm{E} \quad 120^{\circ} \mathrm{E}$

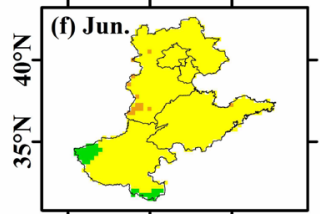

$110^{\circ} \mathrm{E} 115^{\circ} \mathrm{E} 120^{\circ} \mathrm{E}$

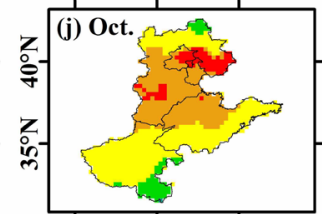

$110^{\circ} \mathrm{E} 115^{\circ} \mathrm{E} 120^{\circ} \mathrm{E}$

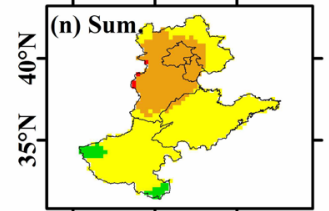

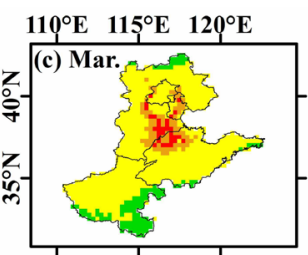

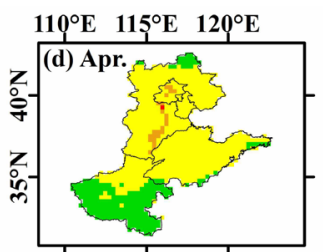

$110^{\circ} \mathrm{E} 115^{\circ} \mathrm{E} 120^{\circ} \mathrm{E}$

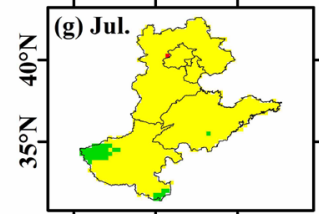

$110^{\circ} \mathrm{E} 115^{\circ} \mathrm{E} 120^{\circ} \mathrm{E}$

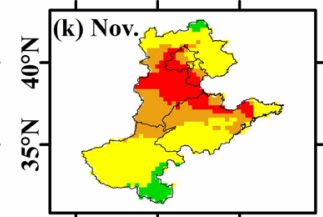

$110^{\circ} \mathrm{E} \quad 115^{\circ} \mathrm{E} 120^{\circ} \mathrm{E}$

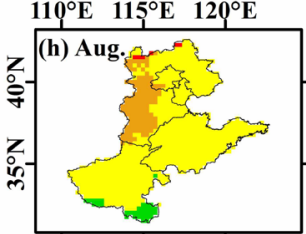

$110^{\circ} \mathrm{E} 115^{\circ} \mathrm{E} 120^{\circ} \mathrm{E}$

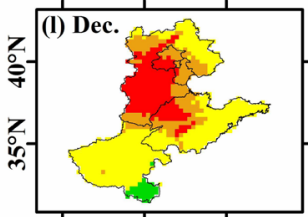

$110^{\circ} \mathrm{E} \quad 115^{\circ} \mathrm{E} 120^{\circ} \mathrm{E}$
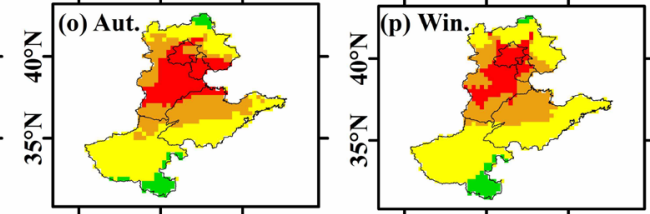

significant upward trend $\left(P^{\prime}<0.01\right)$ significant upward trend $(\mathrm{P}<0.05)$ upward trend (no significant)

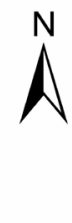

Fig. 6. Monthly and seasonal trends of GGDI in the NCP during 2003-2015 by using the MMK trend test method. 


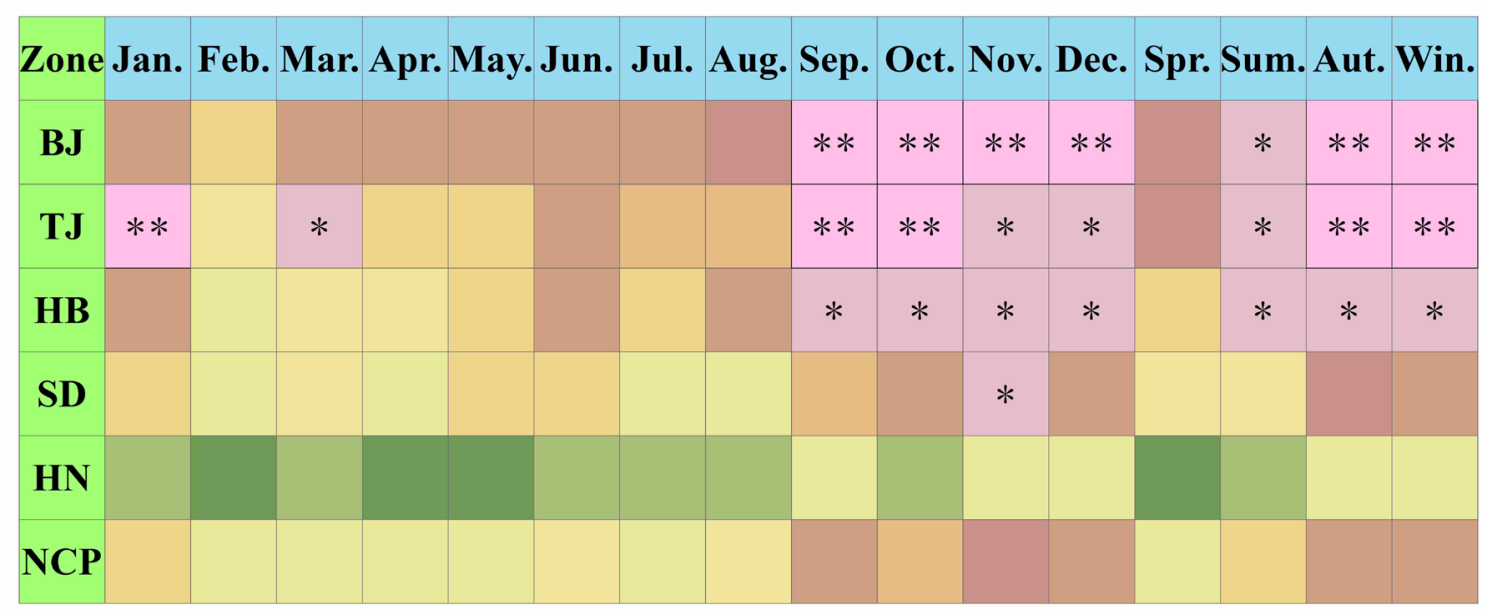

Zs values of GGDI

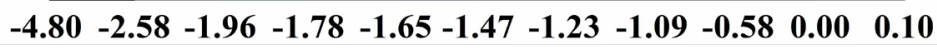

Fig. 7. $Z_{s}$ values of GGDI in the NCP during 2003-2015. “*” and “**” denote significant at 0.05 and 0.01 level, respectively.

\subsection{The links between GGDI and teleconnection factors}

Related studies (Trenberth and David, 2001; Mishra and Singh, 2010; Han et al., 2019) disclosed that droughts were closely linked to teleconnection factors. Thus, the ENSO, AO, PDO and sunspot data were selected to characterize the influences of large-scale climate indices on drought. Additionally, cross wavelet transform method was utilized to reveal the links between GGDI and teleconnection factors in the NCP during 2003-2015 (Fig. 8). In order to avoid boundary effect and high frequency false information of the wavelet transform, the thin solid line in Fig. 8 is the boundary of the cone of influence, with effective spectral regions within it. As shown in Fig. 8a, ENSO has a statistically significant negative correlation with GGDI series at the 95\% confidence level, with a 16-24 month signal in 2005-2007, and a 12-18 month signal in 2009-2011. Fig. 8 b indicates that AO has a prominently positive correlation with GGDI series at the $95 \%$ confidence level, with a 8-12 month signal in 2010-2011. Fig. 8c shows that PDO has a significant positive correlation with GGDI series at the $95 \%$ confidence level, with a 10-14 month signal in 2009-2010; whilst it has a significant negative correlation with GGDI series at the 95\% 
confidence level, with a 8-16 month signal in 2012-2014. Similarly, it can be clearly observed from Fig. 8d that sunspot has an obviously negative correlation with GGDI series at the $95 \%$ confidence level, with a 8-10 month signal in 2011-2012. Besides, there are short-term intermittent resonance periods of 1-8 month between GGDI and teleconnection factors during 2003-2015. In conclusion, the cross wavelet transforms can effectively recognize the links between drought and teleconnection factors. ENSO and sunspot have statistically significant negative dependence with GGDI, and AO has statistically significant positive dependence with GGDI, implying that they play an important role during the drought evolution in the NCP. As for PDO, it has a statistically significant positive and negative correlation with GGDI. Moreover, teleconnection factors have strong influences on drought, and the impacts of ENSO on the droughts are stronger than those of AO, PDO and sunspot.
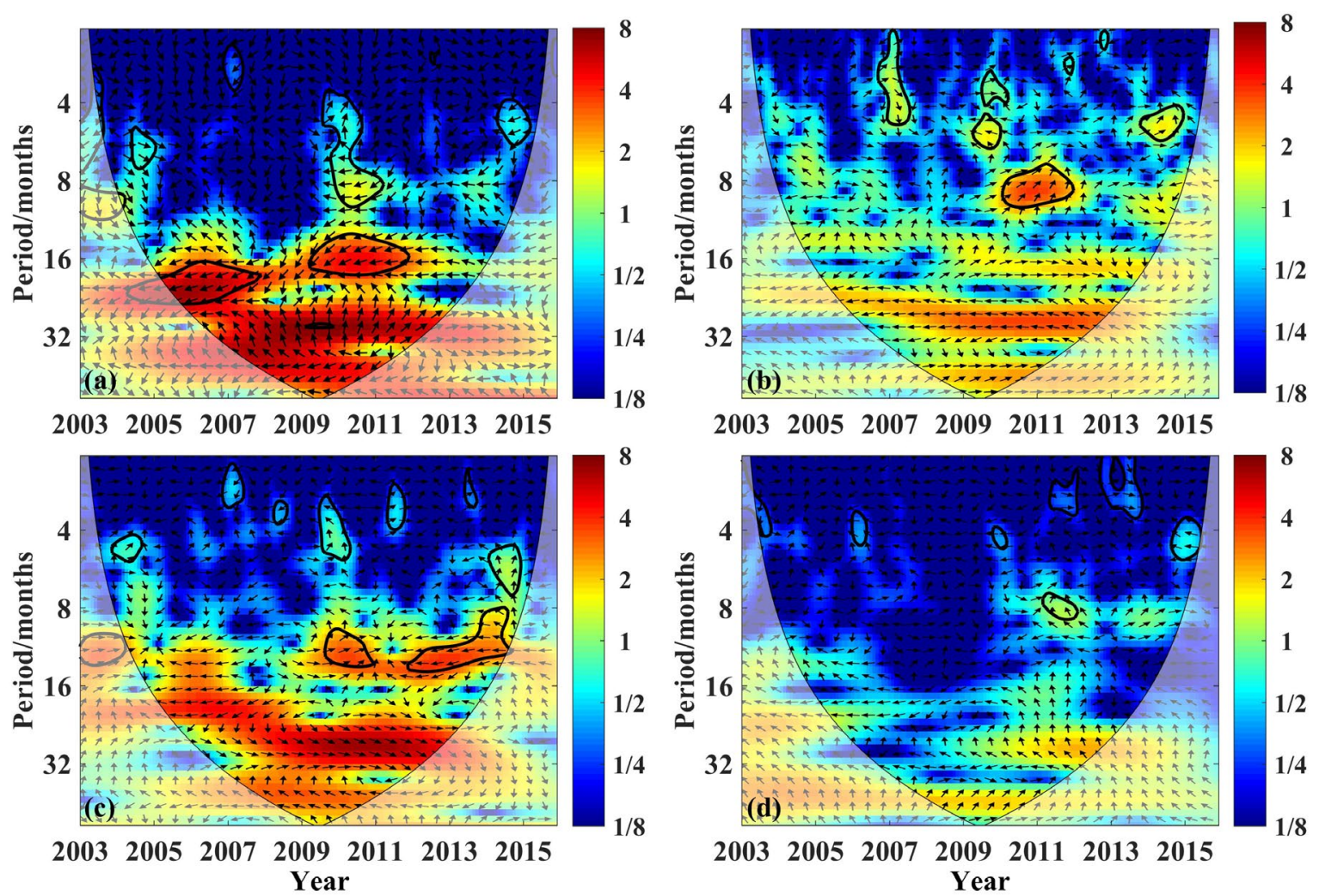

Fig. 8. The cross wavelet transforms between the monthly GGDI and (a) ENSO, (b)

AO, (c) PDO and (d) sunspot data during 2003-2015 in the NCP, respectively. The 
$95 \%$ confidence level against red noise is exhibited as a thick contour, and the relative phase relationship is denoted as arrows (with negative correlations pointing left, and positive associations pointing right). The color bar on the right denotes the wavelet energy.

\section{Discussion}

\subsection{Influence factors of drought}

Under the background of intensive climate change and human activities, it is of great significance to accurately analyze the influence factors of drought for formulating reasonable countermeasures, ensuring food security and maintaining social stability (Liu et al., 2018). In recent years, the decline of precipitation $(-0.71 \mathrm{~mm} / 10 \mathrm{a}, P>0.05)$ and the rise of temperature $\left(0.26{ }^{\circ} \mathrm{C} / 10 \mathrm{a}, P<0.01\right)$ are the main factors of drought in the NCP (A et al., 2016). As for teleconnection factors, people have gradually realized that they play a vital role in the process of drought formation (Dai, 2011). In addition, as found in Section 4.4, the results of cross wavelet transform also revealed that teleconnection factors (ENSO, AO, PDO and sunspot) had intensive impacts on drought evolutions. Specifically, ENSO had the strongest influence on drought in the NCP (Fig. 8), and it was increasing in both frequency and intensity under the global warming (Power et al., 2013). Furthermore, ENSO events can dramatically weaken the intensity of the Walker Circulation, which would cause less precipitation and frequent drought in northern China (Paul and Robert, 1978; Reginald and Yong, 1996; Tobias et al., 2014).

In addition to natural factors, the influence of anthropogenic factors on drought cannot be ignored. As far as we know, water resources are scarce with uneven distributions both spatially and temporally in the NCP (Fang et al., 2010). During crop water requirement season, people have to exploit more groundwater than usual for irrigation, which will lead to a prominent contradiction between supply and demand of water resources, and then 
inevitably trigger drought crisis (Chen et al., 2019a). Obviously, the overexploitation of groundwater for agricultural irrigation, industrial and domestic water demand has resulted in a group of groundwater funnel areas and the emergence of drought, which has brought serious detriment to people's life and property safety. Additionally, the growth of deep-rooted vegetation caused by the implementation of ecological restoration will consume precipitation, deplete groundwater and reduce groundwater level (Yin et al., 2015). The shortage of groundwater resources not only restricts the sustainable development of economy and society, but also makes the occurrence of drought disasters more frequent. Also, excessive greenhouse gases generated by anthropogenic impacts will also promote the development of drought (Bista et al., 2017). According to the survey, the population has increased from 97 million in 1980 to 150 million in 2016 over the NCP (Chen et al., 2019b). Thus, continuous population growth increases the water consumption in daily life of residents, resulting in the over-exploitation of water resources and the aggravation of drought.

The most serious drought event occurred during 2013.08-2014.09 (Fig. 4), which was believed to be due to groundwater depletion (Zhao et al., 2019). Specifically, in July 2014, precipitation decreased about $83.4 \mathrm{~mm}$ and land surface temperature increased about $1.6^{\circ} \mathrm{C}$, causing the worst drought in this month (Chen et al., 2019a). This drought event forced people to exploit more groundwater to compensate the surface water shortage and thereby led to the accelerated groundwater depletion.

Overall, climate change and human activities are the main influence factors of drought. The precipitation showed a non-significant downward trend $(-0.71 \mathrm{~mm} / 10 \mathrm{a}, P>0.05)$, while the terrestrial water storage $(-2.15 \mathrm{~mm} / 10 \mathrm{a}, P<0.01)$ and groundwater storage $(-1.23 \mathrm{~mm} / 10 \mathrm{a}, P<0.01)$ showed a significant downward trend in the NCP during 2003-2015. Compared with climate change, human activities play a dominant role in the 
drought formation in the NCP. Hence, we should strengthen the management system of water resources in many aspects, and vigorously develop water-saving irrigation strategies, adjust crop products, carry out groundwater recharge and strictly control groundwater exploitation (Fang et al., 2010).

\subsection{Delayed effects of GRACE-based drought on precipitation}

The GRACE-based drought showed different degree of delayed effects on precipitation with a certain time-lag ( $\mathrm{Wu}$ et al., 2019). Therefore, we delayed GRACE-based GGDI for 0-3 months (0-month lag, 1-month lag, 2-month lag, 3-month lag), so as to quantitatively investigate the optimal time-lag effect between drought and precipitation in the NCP (Wang et al., 2018a). The time-lag corresponding to the largest $r$ between GGDI and precipitation was considered as the retardation time of drought on precipitation (Fig. 9). Generally, drought showed a delayed response to precipitation, with different time-lags in each subzone. Over the entire plain, the time-lag of drought to precipitation was 1 month in December, with a $r$ value of 0.58 . The time-lag was 2 months in January, March, April, June and October, with $r$ values of $0.66,0.68,0.64,0.75$ and 0.67 , respectively. And the time-lag was 3 months in February, May, July, August, September and November, with $r$ values of $0.69,0.76,0.73,0.73,0.73$ and 0.62 , respectively. In general, the number of 0-month, 1-month, 2-month and 3-month lag was 8, 14, 26 and 24, respectively. The retardation time of drought on precipitation was approximately 2-3 months, with $r$ values ranging from 0.41 to 0.82 . Besides, among all $r$ values, the proportion of $r$ values was $91.67 \%$ and $56.94 \%$ under the significant level of $P<0.05$ and $P$ $<0.01$.

GRACE-based GGDI has delayed effects on precipitation, which is mainly because that GGDI reflects the groundwater drought condition and it takes a long time for precipitation to penetrate from the ground surface to become groundwater (Thomas et al., 
2017). Also, soil water infiltration is a slow process, and it may take several months for rainfall to reach the underground through the root zone (Changnon et al., 1987; Gates et al., 2011). Furthermore, due to the diversities in climate and hydrology, this time-lag will also be different in each subzone of the NCP.

\begin{tabular}{|c|c|c|c|c|c|c|c|c|c|c|c|c|}
\hline Zone & Jan. & Feb & Mar. & Apr. & May & Jun. & Jul. & Aug. & Sep. & Oet & Nov. & Dec. \\
\hline BJ & + & $\Delta$ & $\Delta$ & + & + & + & $\dot{\gamma}$ & 访 & $\Delta$ & + & $\dot{3}$ & + \\
\hline $\mathbf{T J}$ & + & $\Delta$ & + & 0 & + & + & $\sqrt{3}$ & $\Delta$ & $\Delta$ & + & $\Delta$ & $\Delta$ \\
\hline HB & $\underline{t 3}$ & + & + & + & 0 & + & $\Delta$ & 访 & $\Delta$ & $\Delta$ & $\Delta$ & $\Delta$ \\
\hline SD & 0 & 0 & + & 0 & $\Delta$ & + & $\Delta$ & $\Delta$ & + & 0 & $\Delta$ & $\hat{3}$ \\
\hline $\mathbf{H N}$ & 皮 & + & + & th & $\vec{t}$ & $\sqrt{3}$ & 0 & $\Delta$ & + & $\bar{t}$ & 0 & $\sqrt{3}$ \\
\hline $\mathbf{C P}$ & + & $\Delta$ & + & + & $\Delta$ & + & $\Delta$ & $\boldsymbol{\Delta}$ & $\Delta$ & + & $\Delta$ & $\sqrt{3}$ \\
\hline
\end{tabular}

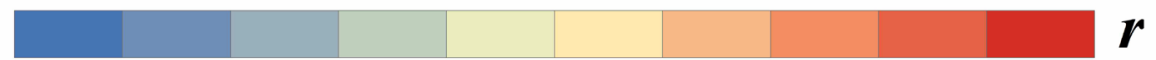

$\begin{array}{llllllllllll}0.41 & 0.47 & 0.56 & 0.62 & 0.66 & 0.69 & 0.71 & 0.73 & 0.76 & 0.78 & 0.82\end{array}$

\section{0-month lag 色 1-month lag + 2-month lag $\triangle$ 3-month lag}

Fig. 9. Time-lags of drought in the NCP, with maximum correlation between

GGDI and precipitation. Red and blue colors indicate higher and lower $r$ values.

\subsection{Uncertainties}

Several areas of uncertainty were encountered in this study. First, in order to avoid the uncertainty caused by the observation error of GRACE satellite and the error in the process of solving the earth gravity field model (Swenson and Wahr, 2006), the latest mascon solutions were adopted to replace the original SHC method. However, due to different background models and data processing strategies, the mascon solutions released by different organizations still have uncertainties. Different hydrological models were considered in the GFZ and JPL mascon solutions for adjusting scale factors, while the CSR mascon solutions selected in this paper only used GRACE data as constraints, without involving other hydrological model errors, thus reducing the existence of uncertainty (Save 
et al., 2012; 2016). As Fig. 3 shows, the uncertainty is about $\pm 7.36 \mathrm{~mm} / \mathrm{month}$ in the NCP. Second, the application of ensemble mean values from multiple hydrological models (Noah, Mosaic, CLM and VIC) was one way to reduce GLDAS uncertainty (Feng et al., 2013; Cao et al., 2015). Because only GLDAS Noah model had the highest spatial resolution consistent with GRACE and TRMM data, we selected GLDAS Noah model with a spatial resolution of $0.25^{\circ} \times 0.25^{\circ}$ to obtain the WSC. Finally, filling in the missing data from GRACE by linear interpolation method may also bring about uncertainties, but this method is simple, prevalent and widely used to handle missing data (Long et al., 2015; Sun et al., 2018). The results obtained from GRACE and GLDAS were basically consistent, thus confirming that the linear interpolation method was feasible and acceptable.

\subsection{Advantages and limitations}

GRACE satellite gravimetry has proven pertinent as an alternate means for detecting drought, especially from the perspective of a scenario of insufficient data on water storages variations (Yirdaw et al., 2008). A series of filtering processes are applied to GRACE products obtained by the traditional SHC method, which can eliminate the influence of various errors, but also weaken the real signal. Thus, it is necessary to use scale factor to recover the signal leakage caused by filtering (Landerer and Swenson, 2012). The performance of newly released GRACE mascon solutions are shown to be equivalent to or superior to traditional-scaled SHC method (Scanlon et al., 2016). In this study, we selected flexible mascon solutions to reflect the change characteristics of terrestrial water storage, and then explored the drought situation in the NCP. Rowlands et al. (2005) compared mascon solutions with SHC method, and found that mascon solutions had great strengths and were superior to the traditional SHC method in some areas. Moreover, although filtering and other post-processing were not implemented in mascon solutions, some researches signified that the results of mascon solutions were consistent with those of SHC method (Save et al., 2016; Sun et al., 2018). Mascon solutions offer several remarkable 
advantages, including constraints applied requiring little or no post-processing, and reduced leakage resulting in increased signal amplitude (Scanlon et al., 2016).

In consideration of limited hydrometeorological data restricting the effective monitoring of drought disaster, GRACE gravity satellite provides an important technical means for drought estimation and prevention. GRACE verification results showed that the accuracy of the GRACE observations was acceptable (Fig. 3). Moreover, Fig. 3 demonstrates that the WSC obtained from GRACE and GLDAS have a similar change trend, which can be found in other research results (Yang and Chen, 2015; Wu et al., 2019). The drought index GGDI is used to identify drought events, which has two advantages: (1) it reflects direct evidence of any surplus and deficit in groundwater availability, and (2) it is a normalized index and can be used to compare drought objectively on the spatio-temporal scale (Thomas et al., 2017). Gong et al. (2018) and Zhao et al. (2019) found that groundwater storages were declining and droughts were aggravating in the NCP, which was similar to the results of the present study. This study successfully identified the drought events in 2013 and 2014, which was consistent with the findings of Zhao et al. (2019) and Chen et al. (2019a). Also, Chen et al. (2019a) identified the worst drought in July 2014. In addition, the area of the study region for obtaining terrestrial water storage using GRACE should be more than $200,000 \mathrm{~km}^{2}$, which is suitable for the NCP (Scanlon et al., 2012).

Furthermore, the relationships between GGDI and large-scale climate indices indicated that teleconnection factors had significant impacts on drought in the NCP. In general, ENSO events had a strong impact on droughts, with a signal ranging from 12 to 24 months, which was consistent with ENSO periodicity of 2-7 years (Dash et al., 2013; Han et al., 2019). Meanwhile, ENSO exhibited a statistically negative correlation with drought, which was consistent with the findings of Huang et al. $(2015,2019)$.

Although GRACE-based GGDI can be used to identify drought characteristics effectively and conveniently, there are still some limitations. GRACE only covers data in 
the last few years, and the results will be more reliable with a longer time series (Thomas et al., 2014). Additionally, the influence of human activities (e.g., mining, regional water diversion) on the earth surface mass change cannot be ignored (Tang et al., 2013). Due to the difficulty in collecting and quantifying relevant data, previous studies have often failed to take it into account. Therefore, how to quantitatively analyze the impact of human activities on water storages is a new research direction in the future.

\section{Conclusions}

GRACE gravity satellite has proven effective as an alternative means for detecting drought, especially from the perspective of a scenario of insufficient data on water storages variations. In this study, the GRACE-based groundwater storage was utilized as a metric for drought characterization in the NCP. The quantitative results of GRACE were reliable and robust, which provided theoretical foundation for further drought investigation. Thus, the temporal evolution, spatial distribution and trend characteristics of drought were quantitatively analyzed in the NCP from 2003 to 2015. Subsequently, the links between GGDI and teleconnection factors were clarified using cross wavelet transform technology. From the results, major conclusions are given as follows:

(1) The GGDI-identified drought showed an upward trend during 2003-2015, with different temporal change characteristics in each subzone. The most significant upward trend of drought occurred in TJ, with a GGDI linear tendency rate of $-0.14 / 10 \mathrm{a}$. Additionally, the most serious drought event occurred during 2013.08-2014.09, with an average GGDI value of -1.36 . On the monthly scale, the worst drought occurred in July 2014, with a minimum GGDI value of -1.96 .

(2) The monthly and seasonal droughts were increasing during 2003-2015 based on MMK trend test method. On the monthly scale, the significant drought increasing trend $(P$ $<0.01)$ with the largest area percentage $(22.4 \%)$ occurred in December. On the seasonal 
scale, the drought area percentage with an upward trend in spring, summer, autumn and winter was $78.2 \%, 96.4 \%, 94.0 \%$ and $94.5 \%$, respectively.

(3) The cross wavelet transform technology can better reveal the links between drought and teleconnection factors. ENSO and sunspot have statistically significant negative dependence with GGDI, whilst AO has statistically significant positive dependence with GGDI. As for PDO, it has a statistically significant positive and negative correlation with GGDI. In general, teleconnection factors have strong influences on drought evolution, and ENSO has the strongest impact on drought in the NCP.

(4) The area of the study region for obtaining terrestrial water storage using GRACE should be more than $200,000 \mathrm{~km}^{2}$, which is suitable for the NCP. The GRACE results will be more reliable with a longer time series. Additionally, the influence of human activities on water storages cannot be ignored.

In summary, this study thoroughly investigated the drought characteristics by using GRACE gravity satellite and revealed the correlations between drought and teleconnection factors. Although the NCP was selected as a case study in this paper, the approach can be applied in other regions as well.

\section{Acknowledgments}

This research was supported by National Key R\&D Program of China (grant number 2018YFC0406505), Key Scientific Research Projects of Henan Colleges and Universities (grant number 19A170014), the National Natural Science Foundation of China (grant number 51779093\&51739009), and Science and technology project of Guizhou Province Water Resources Department (grant number KT201705).

\section{References}


A, D., Zhao, W.J., Qu, X.Y., Jing, R., Xiong, K., 2016. Spatio-temporal variation of vegetation coverage and its response to climate change in North China plain in the last 33 years. Int. J. Appl. Earth Obs. 53, 103-117.

AghaKouchak, A., Feldman, D., Hoerling, M., Huxman, T., Lund, J., 2015. Recognize anthropogenic drought. Nature 524, 409-411.

Asong, Z.E., Wheater, H.S., Bonsal, B., Razavi, S., Kurkute, S., 2018. Historical drought patterns over Canada and their teleconnections with large-scale climate signals. Hydrol. Earth Syst. Sci. 22, 3105-3124.

Bista, P., Norton, U., Ghimire, R., Norton, J.B., 2017. Effects of tillage system on greenhouse gas fluxes and soil mineral nitrogen in wheat (Triticum aestivum, L.)-fallow during drought. J. Arid Environ. 147, 103-113.

Cao, G.L., Scanlon, B.R., Han, D.M., Zheng, C.M., 2016. Impacts of thickening unsaturated zone on groundwater recharge in the North China Plain. J. Hydrol. 537, $260-270$.

Cao, Y.P., Nan, Z.T., Cheng, G.D., 2015. GRACE gravity satellite observations of terrestrial water storage changes for drought characterization in the arid land of Northwestern China. Remote Sens. 7, 1021-1047.

Changnon, S.A., 1987. Detecting drought conditions in Illinois (Vol. 169). Illinois State Water Survey.

Chen, X.J., Mo, X.G., Zhang, Y.C., Sun, Z.G., Liu, Y., Hu, S., Liu, S.X., 2019a. Drought detection and assessment with solar-induced chlorophyll fluorescence in summer maize growth period over North China Plain. Ecol. Indic. 104, 347-356.

Chen, X.Z., Thorp, K.R., Ouyang, Z.Y., Hou, Y., Zhou, B., Li, Y.K., 2019b. Energy consumption due to groundwater pumping for irrigation in the North China Plain. Sci. Total Environ. 669, 1033-1042.

Dai, A., 2011. Drought under global warming: a review. Wires. Clim. Change 2, 45-65. 
Dash, M.K., Pandey, P.C., Vyas, N.K., Turner, J., 2013. Variability in the ENSO-induced southern hemispheric circulation and Antarctic sea ice extent. Int. J. Climatol. 33, 778-783.

Fang, Q.X., Ma, L., Green, T.R., Yu, Q., Wang, T.D., Ahuja, L.R., 2010. Water resources and water use efficiency in the North China Plain: Current status and agronomic management options. Agr. Water Manage. 97, 1102-1116.

Feng, W., Zhong, M., Lemoine, J.M., Biancale, R., Hsu, H.T., Xia, J., 2013. Evaluation of groundwater depletion in North China using the Gravity Recovery and Climate Experiment (GRACE) data and ground-based measurements. Water Resour. Res. 49, $2110-2118$.

Fu, C.S., James, A.L., Wachowiak, M.P., 2012. Analyzing the combined influence of solar activity and El Niño on streamflows across southern Canada. Water Resour. Res. 48, W05507.

Gates, J.B., Scanlon, B.R., Mu, X.M., Zhang, L., 2011. Impacts of soil conservation on groundwater recharge in the semi-arid Loess Plateau, China. Hydrogeol. J. 19, $865-875$.

Ghil, M., Allen, M.R., Dettinger, M.D., Ide, K., Kondrashov, D., Mann, M.E., Robertson, A.W., Saunders, A., Tian, Y., Varadi, F., Yiou, P., 2002. Advanced spectral methods for climatic time series. Rev. Geophys. 40, 1-41.

Gong, H.L., Pan, Y., Zheng, L.Q., Li, X.J., Zhu, L., Zhang, C., Huang, Z.Y., Li, Z.P., Wang, H.G., Zhou, C.F., 2018. Long-term groundwater storage changes and land subsidence development in the North China Plain (1971-2015). Hydrogeol. J. 26, 1417-1427.

Guo, Y., Huang, S.Z., Huang, Q., Wang, H., Fang, W., Yang, Y.Y., Wang, L., 2019. Assessing socioeconomic drought based on an improved Multivariate Standardized Reliability and Resilience Index. J. Hydrol. 568, 904-918. 
Han, Z.M., Huang, S.Z., Huang, Q., Leng, G.Y., Wang, H., He, L., Fang, W., Li, P., 2019. Assessing GRACE-based terrestrial water storage anomalies dynamics at multi-timescales and their correlations with teleconnection factors in Yunnan Province, China. J. Hydrol. 574, 836-850.

Hosseini-Moghari, S.M., Araghinejad, S., Ebrahimi, K., Tourian, M.J., 2019. Introducing modified total storage deficit index (MTSDI) for drought monitoring using GRACE observations. Ecol. Indic. 101, 465-475.

Hu, Y., 2013. Drought Risk Assessment of Winter Wheat and Summer Maize Rotation Planting Region in North China Plain. Chinese Academy of Agricultural Sciences.

Huang, S.Z., Huang, Q., Chang, J.X., Zhu, Y.L., Leng, G.Y., Xing, L., 2015. Drought structure based on a nonparametric multivariate standardized drought index across the Yellow River basin, China. J. Hydrol. 530, 127-136.

Huang, S.Z., Huang, Q., Chang, J.X., Leng, G.Y., 2016. Linkages between hydrological drought, climate indices and human activities: a case study in the Columbia River Basin. Int. J. Climatol. 36, 280-290.

Huang, S.Z., Wang, L., Wang, H., Huang, Q., Leng, G.Y., Fang, W., Zhang, Y., 2019. Spatio-temporal characteristics of drought structure across China using an integrated drought index. Agr. Water Manage. 218, 182-192.

Huffman, G.J., Adler, R.F., Bolvin, D.T., Gu, G.J., Nelkin, E.J., Bowman, K.P., Hong, Y., Stocker, E.F., Wolff, D.B., 2007. The TRMM multisatellite precipitation analysis (TMPA): quasi-global, multiyear, combined-sensor precipitation estimates at fine scales. J. Hydrometeorol. 8, 38-55.

Landerer, F.W., Swenson, S.C., 2012. Accuracy of scaled GRACE terrestrial water storage estimates. Water Resour. Res. 48, W04531. 
Li, X.X., Ju, H., Garré, S., Yan, C.R., Batchelor, W.D., Liu, Q., 2017. Spatiotemporal variation of drought characteristics in the Huang-Huai-Hai Plain, China under the climate change scenario. J. Integr. Agr. 16, 2308-2322.

Lin, M., Biswas, A., Bennett, E.M., 2019. Spatio-temporal dynamics of groundwater storage changes in the Yellow River Basin. J. Environ. Manage. 235, 84-95.

Liu, X.F., Pan, Y.Z., Zhu, X.F., Yang, T.T., Bai, J.J., Sun, Z.L., 2018. Drought evolution and its impact on the crop yield in the North China Plain. J. Hydrol. 564, 984-996.

Long, D., Shen, Y.J., Sun, A., Hong, Y., Longuevergne, L., Yang, Y.T., Li, B., Chen, L., 2014. Drought and flood monitoring for a large karst plateau in Southwest China using extended GRACE data. Remote Sens. Environ. 155, 145-160.

Long, D., Yang, Y.T., Wada, Y., Hong, Y., Liang, W., Chen, Y.N., Yong, B., Hou, A.Z., Wei, J.F., Chen, L., 2015. Deriving scaling factors using a global hydrological model to restore GRACE total water storage changes for China's Yangtze River Basin. Remote Sens. Environ. 168, 177-193.

Ma, F., Ye, A.Z., You, J.J., Duan, Q.Y., 2018. 2015-16 floods and droughts in China, and its response to the strong E1 Niño. Sci. Total Environ. 627, 1473-1484.

Ma, S.Y., Wu, Q.X., Wang, J., Zhang, S.Q., 2017. Temporal evolution of regional drought detected from GRACE TWSA and CCI SM in Yunnan Province, China. Remote Sensing. 9, 1124.

Mishra, A.K., Singh, V.P., 2010. A review of drought concepts. J. Hydrol. 391, 202-216.

Mishra, A.K., Singh, V.P., 2011. Drought modeling-A review. J. Hydrol. 403, 157-175.

Paul, R.J., Robert, M.C., 1978. A study of the Southern Oscillation and Walker Circulation phenomenon. Mon. Weather. Rev. 106, 1433-1451.

Power, S., Delage, F., Chung, C., Kociuba, G., Keay, K., 2013. Robust twenty-first-century projections of El Niño and related precipitation variability. Nature 502, 541-545. 
Reginald, E.N., Yong, Z., 1996. Walker circulation and tropical upper tropospheric water vapor. J. Geophys. Res. 101 (D1), 1961-1974.

Rodell, M., Houser, P.R., Jambor, U., Gottschalck, J., Mitchell, K., Meng, C., Arsenault, K., Cosgrove, B., Radakovich, J., Bosilovich, M., Entin, J.K., Walker, J.P., Lohmann, D., Toll, D., 2004. The Global Land Data Assimilation System. Bull. Am. Meteorol. Soc. $85,381-394$.

Rowlands, D.D., Luthcke, S.B., Klosko, S.M., Lemoine, F.G.R., Chinn, D.S., McCarthy, J.J., Cox, C.M., Anderson, O.B., 2005. Resolving mass flux at high spatial and temporal resolution using GRACE intersatellite measurements. Geophys. Res. Lett. 32, L04310.

Save, H., Bettadpur, S., Tapley, B.D., 2012. Reducing errors in the GRACE gravity solutions using regularization. J. Geodesy 86, 695-711.

Save, H., Bettadpur, S., Tapley, B.D., 2016. High-resolution CSR GRACE RL05 mascons. J. Geophys. Res. Solid Earth 121, 7547-7569.

Scanlon, B.R., Longuevergne, L., Long, D., 2012. Ground referencing GRACE satellite estimates of groundwater storage changes in the California Central Valley, USA. Water Resour. Res. 48, W04520.

Scanlon, B.R., Zhang, Z.Z., Save, H., Wiese, D.N., Landerer, F.W., Long, D., Longuevergne, L., Chen, J.L., 2016. Global evaluation of new GRACE mascon products for hydrologic applications. Water Resour. Res. 52, 9412-9429.

Sinha, D., Syed, T.H., Reager, J.T., 2019. Utilizing combined deviations of precipitation and GRACE-based terrestrial water storage as a metric for drought characterization A case study over major Indian river basins. J. Hydrol. 572, 294-307.

Sun, Z.L., Zhu, X.F., Pan, Y.Z., Zhang, J.S., Liu, X.F., 2018. Drought evaluation using the GRACE terrestrial water storage deficit over the Yangtze River Basin, China. Sci. Total Environ. 634, 727-738. 
Swenson, S., Wahr, J., 2006. Post-processing removal of correlated errors in GRACE data. Geophys. Res. Lett. 33, L08402.

Tang, Q.H., Zhang, X.J., Tang, Y., 2013. Anthropogenic impacts on mass change in North China. Geophys. Res. Lett. 40, 3924-3928.

Thomas, A.C., Reager, J.T., Famiglietti, J.S., Rodell, M., 2014. A GRACE-based water storage deficit approach for hydrological drought characterization. Geophys. Res. Lett. $41,1537-1545$.

Thomas, B.F., Famiglietti, J.S., Landerer, F.W., Wiese, D.N., Molotch, N.P., Argus, D.F., 2017. GRACE Groundwater Drought Index: Evaluation of California Central Valley groundwater drought. Remote Sens. Environ. 198, 384-392.

Tobias, B., Dietmar, D., Thomas, M., Scott, B.P., 2014. The eastward shift of the Walker Circulation in response to global warming and its relationship to ENSO variability. Clim. Dyn. 43, 2747-2763.

Torrence, C., Compo, G.P., 1998. A practical guide to wavelet analysis. Bull. Am. Meteorol. Soc. 79, 61-78.

Trenberth, K.E., David, P.S., 2001. Indices of El niño evolution. J. Clim. 14, 1697-1701.

Vicente-Serrano, S.M., Beguería, S., López-Moreno, J.I., 2010. A multiscalar drought index sensitive to global warming: The Standardized Precipitation Evapotranspiration Index. J. Clim. 23, 1696-1718.

Walwer, D., Calais, E., Ghil, M., 2016. Data-adaptive detection of transient deformation in geodetic networks. J. Geophys. Res. Solid Earth 121, 2129-2152.

Wang, H.J., Chen, Y.N., Pan, Y.P., Li, W.H., 2015. Spatial and temporal variability of drought in the arid region of China and its relationships to teleconnection indices. J. Hydrol. 523, 283-296. 
Wang, F., Wang, Z.M., Yang, H.B., Zhao, Y., Li, Z.H., Wu, J.P., 2018a. Capability of remotely sensed drought indices for representing the spatio-temporal variations of the meteorological droughts in the Yellow River Basin. Remote Sens. 10, 1834.

Wang, F., Yang, H.B., Wang, Z.M., Zhang, Z.Z., Li, Z.H., 2019. Drought evaluation with CMORPH satellite precipitation data in the Yellow River Basin by using Gridded Standardized Precipitation Evapotranspiration Index. Remote Sens. 11, 485.

Wang, S.S., Mo, X.G., Hu, S., Liu, S.X., Liu, Z.J., 2018b. Assessment of droughts and wheat yield loss on the North China Plain with an aggregate drought index (ADI) approach. Ecol. Indic. 87, 107-116.

Wu, Q.F., Si, B.C., He, H.L., Wu, P.T., 2019. Determining regional-scale groundwater recharge with GRACE and GLDAS. Remote Sens. 11, 154.

Xu, Y.P., Booij, M.J., Tong, Y.B., 2010. Uncertainty analysis in statistical modeling of extreme hydrological events. Stoch. Env. Res. Risk A. 24, 567-578.

Yang, P., Chen, Y.N., 2015. An analysis of terrestrial water storage variations from GRACE and GLDAS: The Tianshan Mountains and its adjacent areas, central Asia. Quatern. Int. 358, 106-112.

Yi, H., Wen, L.X., 2016. Satellite gravity measurement monitoring terrestrial water storage change and drought in the continental United States. Sci. Rep. 6, 19909.

Yin, L.H., Zhou, Y.X., Huang, J.T., Wenninger, J., Zhang, E.Y., Hou, G.C., Dong, J.Q., 2015. Interaction between groundwater and trees in an arid site: Potential impacts of climate variation and groundwater abstraction on trees. J. Hydrol. 528, 435-448.

Yirdaw, S.Z., Snelgrove, K.R., Agboma, C.O., 2008. GRACE satellite observations of terrestrial moisture changes for drought characterization in the Canadian Prairie. J. Hydrol. 356, 84-92.

Zhang, B.Q., He, C.S., 2016. A modified water demand estimation method for drought identification over arid and semiarid regions. Agr. Forest Meteorol. 230-231, 58-66. 
Zhang, Y.F., He, B., Guo, L.L., Liu, D.C., 2019. Differences in response of terrestrial water storage components to precipitation over 168 global river basins. J. Hydrometeorol. 20, 1981-1999.

Zhang, Y.Q., You, Q.L., Chen, C.C., Li, X., 2017. Flash droughts in a typical humid and subtropical basin: A case study in the Gan River Basin, China. J. Hydrol. 551, $162-176$.

Zhao, Q., Zhang, B., Yao, Y.B., Wu, W.W., Meng, G.J., Chen, Q., 2019. Geodetic and hydrological measurements reveal the recent acceleration of groundwater depletion in North China Plain. J. Hydrol. 575, 1065-1072. 